\section{MAL-ESTAR NO TRABALHO: REPRESENTAÇÕES DE TRABALHADORES DE UM ÓRGÃO PÚBLICO DE PESQUISA}

\author{
Malaise at Work: Representations of the Workers from a \\ Research Institute
}
Malestar en el Trabajo: Las Representaciones de los Empleados de una Agencia de Investigación
Mal-être au Travail: Représentations des Travailleurs d'un Organisme Public de Recherche

\begin{abstract}
Resumo
Nas últimas décadas, especialmente em função dos efeitos da reestruturação produtiva, o malestar no trabalho despontou como objeto de investigação no campo das ciências do trabalho e da saúde. O objetivo geral deste estudo foi avaliar a percepção dos servidores e colaboradores de um órgão de pesquisa sobre o mal-estar no contexto de trabalho. A demanda pela pesquisa partiu do órgão em questão, devido a diversas intercorrências relacionadas à saúde e ao bemestar dos trabalhadores da casa, como absenteísmo e aumento dos casos de licença-saúde. Participaram do estudo 275 trabalhadores, com idade média de 37,70 anos ( $D P=12,40$ ), o que corresponde a $33,86 \%(\mathrm{~N}=812)$ do total de trabalhadores da casa no momento da pesquisa. Como instrumento, foi utilizada a versão eletrônica do Inventário de Avaliação de Qualidade de Vida no Trabalho - IAQVT. Os resultados evidenciam que as vivências de mal-estar no trabalho estão relacionadas a: 1) gestão organizacional; 2) espaço de trabalho inadequado e falta de planejamento; 3) desigualdade de tratamento entre cargos e carreira; 4) injustiças e falta de autonomia. Tais dados reforçam a necessidade de mudanças imediatas no contexto de trabalho. Conclui-se o artigo apresentando possibilidades de intervenção e sugestões para a promoção do bem-estar no trabalho.
\end{abstract}

Palavras-chave: mal-estar no trabalho; qualidade de vida no trabalho; órgão público; organização do trabalho; condições de trabalho.

\begin{abstract}
In recent decades, due to effects of restructuring process, the malaise at work emerged as an object of research in the science field of work and health. The aim of this study was to evaluate the perception of servers and employees of a research body about the malaise in the work context. The demand for the research came from the organ in question, due to various complications related to health and welfare of workers home as absenteeism and increased cases of sick leave. The study included 275 workers, with an average age of 37.70 years $(S D=12.40)$, which corresponds to $33.86 \%(N=812)$ of the total workforce of the house at the time of the survey. As a tool, we used the electronic version of Inventory of Quality Assessment of Working Life. The results show that the experiences of malaise at work are related to: 1) organizational management, 2) inadequate workspace and lack of planning, 3) unequal treatment between jobs and careers; 4) injustice and lack of autonomy. This data reinforce the need for immediate changes in the work context. We concluded the paper by presenting opportunities for intervention and suggestions for promoting well-being at work.
\end{abstract}

Keywords: malaise at work; quality of work life; public agency; working organization; working conditions.
Artigo Original
Helena Karla Barbosa de Lima ${ }^{(4)}$

1) Doutorado em Psicologia Social, do Trabalho e das Organizações (PG-PSTO, UnB). Professora Adjunta no Instituto de Psicologia, Universidade de Brasília.

2) Psicóloga pela Universidade de Brasília.

3) Psicóloga pela Universidade de Brasília. Mestranda do Programa de Pós-Graduação em Psicologia Social, do Trabalho e das Organizações (PG-PSTO, UnB), Universidade de Brasília.

4) Psicóloga pela Universidade Federal da Paraíba. Mestre em Psicologia Social, do Trabalho e das Organizações (PGPSTO, UnB).
Recebido em: 15/09/2013 Revisado em: 02/06/2014 Aceito em: 18/06/2014 


\section{Resumen}

En las últimas décadas, debido a los efectos del proceso de reestructuración, el malestar en el trabajo surgió como un objeto de investigación en el campo de las ciencias del trabajo y la salud. El objetivo de este estudio fue evaluar la percepción de los servidores y empleados de un cuerpo de investigación sobre el malestar en el contexto laboral. La demanda de esta investigación provino del órgano en cuestión, debido a diversas complicaciones relacionadas a la salud y el bienestar de los trabajadores a domicilio como el absentismo y el aumento de los casos de baja por enfermedad. El estudio incluyó 275 trabajadores, con edad media de 37,70 años $(D E=12,40)$, que corresponde al 33,86\% $(N=812)$ del total de trabajadores de la casa en el momento de la encuesta. Como herramienta, hemos utilizado la versión electrónica del Inventario de Evaluación de la Calidad de Vida Laboral. Los resultados muestran que las experiencias de malestar en el trabajo están relacionados: 1) la gestión de la organización, 2) área de trabajo inadecuadas y la falta de planificación, 3) la desigualdad de trato entre los trabajos y carreras, y 4) la injusticia y la falta de autonomía. Estos datos refuerzan la necesidad de cambios inmediatos en el contexto laboral. Se concluye el documento de presentación de oportunidades de intervención y sugerencias para promover el bienestar en el trabajo.

Palabras clave: malestar en el trabajo; la calidad de la vida laboral; agencia pública; organización del trabajo; las condiciones de trabajo.

\section{Résumé}

Au cours des dernières décennies, en raison des effets du processus de restructuration, le malaise au travail est apparu comme un objet de recherche dans le domaine des sciences du travail et de la santé. Le but de cette étude était d'évaluer la perception des serveurs et des employés d'un organisme de recherche sur le malaise dans le contexte du travail. La demande pour cette recherche provient de l'organe en question, en raison de plusieurs complications liées à la santé et au bien-être des travailleurs à domicile comme l'absentéisme et une augmentation des cas de congé de maladie. L'étude a inclus 275 travailleurs, avec un âge moyen de 37,70 ans (écart type 12,40), ce qui correspond à 33,86\% $(N=812)$ de l'effectif total de la maison au moment de l'enquête. Comme outil, nous avons utilisé la version électronique de l'inventaire des évaluations de la qualité de vie au travail. Les résultats montrent que les expériences de malaise au travail sont liés à: 1) la gestion organisationnelle, 2) l'espace de travail inadéquates et le manque de planification, 3) l'inégalité de traitement entre les emplois et les carrières; 4) l'injustice et le manque d'autonomie. Ces données renforcent la nécessité de changements immédiats dans le contexte du travail. Nous concluons le papier en présentant les possibilités d'intervention et des suggestions pour promouvoir le bien-être au travail.

Mots-clés: malaise au travail; la qualité de vie au travail; organisme public; organisation du travail; les conditions de travail.
O mal-estar no trabalho é um tema atual e vem ganhando espaço em publicações nas ciências do trabalho e da saúde (Ferreira \& Seidl, 2009). O início dos estudos sobre a temática parece se situar na década de 1960. Neste momento, um conjunto de fatores socioeconômicos coloca em cheque o até então exitoso trajeto do capitalismo, que priorizava a produção e uma estrutura social instrumentalizada. A exploração da mão-de-obra nas indústrias chega ao seu esgotamento, demonstrado por meio dos recorrentes acidentes de trabalho e do volume significativo de trabalhadores acometidos por doenças físicas e psicológicas relacionadas ao desgaste no trabalho (síndrome das telefonistas, surdez em fábricas de tecido, por exemplo). Além disso, greves e pressões coletivas por modificações no estado de coisas no âmbito econômico, político e social, que redundaram na adoção de modelos mais "aceitáveis" ou ajustados às aspirações identificáveis, haja visto o Welfare State no espaço da Comunidade Econômica Europeia à época.

A literatura aponta certo consenso no que diz respeito aos efeitos negativos e alienantes da existência de malestar no trabalho no contexto industrial e pós-industrial (Bendassolli, 2011). A percepção dos efeitos do malestar no trabalho é intensa e ganha destaque tanto nos ambientes de trabalho quanto na literatura. De acordo com Abrahão (2000), pode-se verificar o impacto das inovações tecnológicas sobre o modo de produção tanto nas relações de troca, quanto nas relações de produção propriamente ditas. O principal efeito das inovações ocorridas na década de 1980 e 1990 manifesta-se em mudanças nas formas de cooperação, influindo diretamente na atividade humana, na matéria prima que se aplica o trabalho e nos meios e instrumentos utilizados pelos trabalhadores.

No que se refere aos serviços públicos, como é o caso do instituto de pesquisa campo desta investigação, verificase uma alteração em sua lógica de funcionamento, marcada por traços da Reestruturação Produtiva (Baumgarten, 2006), passando tais serviços, então, a serem concebidos como estruturas do sistema produtivo capitalista, quer seja por sua privatização, quer seja pela nova forma de gestão que se instituiu, baseada em controle excessivo, metas atreladas à racionalidade do capital e à lógica dos mercados (Antunes \& Alves, 2004).

Se, por um lado, as transformações na gestão levaram, ao menos inicialmente, a maior produtividade e ao cumprimento de novas demandas de órgãos do estado (no caso do judiciário brasileiro, por exemplo, o cumprimento de metas impostas pelo Conselho Nacional de Justiça), por outro lado dados indicam que a pressão por resultados acima da média a curto prazo, associada ao contingente insuficiente de trabalhadores e, ainda, o cenário de precarização da organização do trabalho, levam ao aumento 
do custo humano no desenvolvimento das atividades, gerando mal-estar e, por vezes, até mesmo adoecimento (Albuquerque, 2011; Almeida, 2007; Andrade, 2011; Antloga, Maia, Cunha, \& Peixoto, 2014; Branquinho, 2010; Brusiquese \& Ferreira, 2012; Daniel, 2012; Feitosa, 2010; Fernandes, 2013; Figueira, 2014; Medeiros, 2012). Neste sentido, percebe-se que, para cumprir seu propósito de promover cidadania para a população, os trabalhadores acabam, eles mesmos, comprometendo sua cidadania, na medida em que não podem ter seus direitos básicos, como o de usufruir de saúde no trabalho, assegurados.

Desta feita, verifica-se que o contexto do serviço público tem sido marcado por novas exigências relacionadas ao trabalho (Ferreira, Ferreira, Antloga, \& Bergamaschi, 2009; Ferreira, 2013), caracterizadas por:

$\checkmark$ Quadro reduzido de trabalhadores e intensificação do trabalho: a despeito do grande volume de contratações no serviço público nos últimos 10 anos, o aumento da população e da demanda por prestação de serviços de qualidade culminou em um cenário de insuficiência de pessoas que trabalham e intensificação das atividades (Dal Rosso, 2008);

$\checkmark$ Gestão flexível da produção e do trabalho: Consiste na operacionalização da especialização flexível, que leva ao acúmulo constante de novas tarefas e à flexibilidade funcional, que inclui rodízio de atividades, polivalência e multiqualificação. Desta forma, o trabalhador se vê marginalizado do sentido do seu próprio trabalho, uma vez que não há tempo para que ele se qualifique e se identifique com suas atividades. Apesar disto, espera-se que haja crescente responsabilidade, autonomia para execução de tarefas complexas e criatividade, em um processo "esquizofrenizante" em si mesmo.

$\checkmark$ Inserção de novas tecnologias e formas de produção: não só a informatização, mas também modelos de gestão produtivistas e de alta exigência marcam um contexto em que o trabalhador tem que se adaptar às novas tecnologias, ou seja, "formatar-se" a diversos contextos, mas ao mesmo tempo tem que ser criativo e "pensar fora da caixa"; tem que assumir responsabilidades e ter autonomia, a despeito de contextos com rígido controle;

$\checkmark$ Aumento das expectativas dos clientes/usuários por serviços mais ágeis e eficientes: se, por um lado, a melhora da oferta e da qualidade de serviços é inequívoca, por outro pode-se questionar o caráter político desta oferta. Neste sentido, verifica-se que muitas promessas de melhoras de serviços são feitas e, para cumpri-las, sacrifica-se o trabalhador que precisa realizar o trabalho que lhe é imposto, muitas vezes sem a estrutura adequada para tal.

É com base nesse cenário de reestruturação produtiva e das novas exigências que um conjunto de indicadores críticos aparece. Relacionados à produção, surgem erros frequentes na realização de tarefas, retrabalho, perda e desperdício de material, danificação de máquinas e equipamentos, queda e redução da produtividade e da qualidade. Além desses, os indicadores críticos sobre os trabalhadores são absenteísmo crônico, acidentes, doenças do trabalho e licenças-saúde, desmotivação, rotatividade e sobrecarga de trabalho, dentre outros. A soma desses indicadores impacta usuários e consumidores e se manifestam sob a forma de queixas e reclamações da qualidade de serviços e produtos e insatisfação quanto à qualidade dos serviços prestados (Ferreira, 2008a, 2013).

Em contrapartida ao expressivo volume dos citados indicadores, nos últimos anos, verifica-se um sensível aumento da preocupação com a saúde dos trabalhadores do serviço público brasileiro (Guimarães, 2009). Isso se deu também em função dos diversos apontamentos acerca do mal-estar no trabalho em tal contexto e da necessidade de dar cumprimento ao artigo 200 (parágrafos II, III, V e VIII) da Constituição Brasileira, que trata da promoção da saúde do trabalhador no contexto do Sistema Único de Saúde e, ainda, visando atender as determinações da OIT no que se refere a trabalho decente (Ferreira, 2013). A consequência de todas estas preocupações foi a instituição do Subsistema Integrado de Atenção à Saúde do Servidor Público Federal - SIASS, por meio da Portaria Normativa ${ }^{\circ} 03 / 2009$, pelo Ministério do Planejamento brasileiro, órgão responsável por determinar políticas de organização e suporte para todo o serviço público no país.

No contexto do subsistema, prevê-se a promoção de programas de Qualidade de Vida no Trabalho que considerem a organização do trabalho, as condições de trabalho e o relacionamento socioprofissional, visando à melhoria dos contextos laborais por meio da participação ativa dos trabalhadores. Tal diretriz encontra-se, portanto, em alinhamento com a proposta deste estudo, de dar voz às pessoas que trabalham para atender suas demandas por mudanças no contexto de trabalho.

$\mathrm{O}$ instituto em que foi realizada esta pesquisa tratase de um órgão público do governo federal brasileiro. A demanda pelo estudo partiu da própria organização que identificou, com base em dados epidemiológicos do serviço de saúde e em uma pesquisa de clima organizacional, realizada dois anos antes desta intervenção, a presença de diversos indicadores críticos (aumento de afastamento e licenças por doenças mentais como ansiedade, depressão; e 
aumento de afastamentos e ocorrência de adoecimentos de fundo "emocional", como gastrite, alergias inespecíficas, enxaquecas e asmas brônquicas).

Nos últimos anos, o instituto, especialmente sua área fim (a que viabiliza as pesquisas, as coletas de dados e suas análises), tem sido alvo de muita pressão por parte das áreas do governo que lhe demandam as pesquisas. Em conversas informais com os trabalhadores, verificou-se o desenvolvimento de novas ações por parte do governo do país tem se ancorado majoritariamente nos dados fornecidos pelos resultados das pesquisas realizadas por eles. O volume de ações governamentais que demandam resultados de pesquisa aumentou muito nos últimos anos e, em consequência, avalia-se que o trabalho dos pesquisadores praticamente dobrou nos últimos 10 anos.

$\mathrm{O}$ aumento da demanda de trabalho para a área fim impacta diretamente a área meio, que precisa oferecer maior suporte para todas as ações realizadas pelos pesquisadores, ou seja, a área fim. Neste sentido, o volume de trabalho referente à elaboração de editais, contratação de pessoas e empresas para dar viabilidade ao trabalho dos pesquisadores, bem como a avaliação do trabalho executado e seu impacto na sociedade aumentou expressivamente e tem estado sob o olhar atento do governo federal e da sociedade. Assim, as marcas do mal-estar no trabalho neste instituto não parecem se diferenciar das identificadas em outros órgãos do serviço público brasileiro.

Apesar da inequívoca presença do mal-estar no trabalho no cotidiano social e do aumento do volume de pesquisas sobre o tema (Araújo, Sena, Viana, \& Araújo, 2006; Aznar, Rodriguez, \& Aznar, 2006; Beatriz, 2010; Chavez, 2009; Gil-Monte \& Peiró, 1997; Maciel, Sena, \& Sabóia, 2006; Maslach \& Leiter, 1999; Neto, 2010; Sá, 2001; Silva, 2005; Timm, Mosquera, \& Stobaus, 2010), a definição clara do termo é residual na literatura de ciências do trabalho e geralmente vem associada às questões de sofrimento no trabalho, como se sofrimento derivasse do mal-estar, e vice-versa. Considerando a falta de clareza conceitual sobre o tema, a análise da literatura na área pode ser útil para compreensão do que se trata quando se fala de mal-estar no trabalho.

A pesquisa de Aznar, Rodriguez e Aznar (2006) teve como objetivo relacionar estresse e mal-estar em 357 professores das Ilhas Canárias na Espanha. Entretanto, não houve uma definição de mal-estar e não houve mensuração do construto. O mal-estar é visto como uma consequência do enfrentamento do estresse, centrado na emoção.

O termo "mal-estar docente", utilizado nos estudos de Araujo et al. (2006), Silva (2005) e Timm, Mosquera e Stobaus (2010), está associado ao ambiente profissional essencialmente focado nas condições de trabalho (salas de aula, materiais disponíveis, infra-estrutura, temperatura e postura, por exemplo). Na mesma perspectiva, Chavez (2009) associa mal-estar às condições de trabalho. Nos resultados destas pesquisas aparecem questões associadas também à sobrecarga e ao significado do trabalho, evidenciando a importância de se estudar a organização do trabalho enquanto fonte promotora ou não de bem-estar.

Beatriz (2010) e Silva (2005) utilizam o conceito de sofrimento de Dejours para definir mal-estar, como se um conceito significasse o outro. Ademais, Sá (2001), Timm, Mosquera e Stobaus (2010) lançam mão do termo malestar na civilização de Freud (1930/1996) para definir mal-estar nos contextos estudados. De certa forma, parece haver se consolidado uma intelecção de que o mal-estar da civilização, descrito por Freud é o próprio mal-estar no trabalho (Bendassolli, 2011), porque esta civilização se define pelos seus resultados, e estes não originam senão da atividade laboral.

Maciel, Sena e Sabóia (2006) analisaram a percepção de mal-estar no trabalho de profissionais de uma cooperativa de trabalho autogestionário. Duas fontes de mal-estar foram constatadas: (1) a relação dos cooperados com os ganhos e benefícios oriundos do trabalho (mal-estar com relação a sua atual situação de trabalho) e (2) as relações entre os profissionais em diferentes posições na estrutura da cooperativa. Entretanto, não há definição do que é mal-estar no trabalho.

Na pesquisa realizada por Sousa e Dela Coleta (2012) sobre os fatores que contribuem para ou prejudicam o bemestar no trabalho em duas secretarias de saúde municipais do Triângulo Mineiro e quatro setores de saúde pública da Universidade Federal de Uberlândia, 66 psicólogos relataram que as fontes que prejudicam o bem-estar no trabalho estão relacionadas à: (1) problemas de gestão/ instituição, (2) problemas com a equipe, (3) falta de condições de trabalho, (4) prejuízos à saúde e ao bem-estar, (5) dificuldades do paciente, (6) falta de reconhecimento, (7) frustrações, (8) políticas públicas, (9) ambiente de trabalho, e (10) relacionamento com a chefia.

$\mathrm{Na}$ tentativa de conceituar mal-estar no trabalho, Ferreira e Seidl (2009) examinaram, por meio de dados empíricos resultantes de pesquisa com 1.164 bancários do serviço público brasileiro, as variáveis que compõem o tópico correlacionando-as com aspectos da cultura organizacional. Os resultados evidenciaram cinco núcleos temáticos ociosidade, salário e reciprocidade; hostilidade e condições físicas; discriminação para com os terceirizados; carreira e estilo de chefia; e trabalho repetitivo, controle e divisão de tarefas - que revelaram traços da cultura organizacional. Tais elementos serviram de base para delinear os principais focos do mal-estar no trabalho, por meio das correlações com 
as noções de bem-estar no trabalho e contexto de produção de bens e serviços. Em suma, para os autores, o mal-estar no trabalho relacionar-se-ia a: (a) Estado emocional negativo ou de sofrimento, resultante das experiências de trabalho; (b) Desempenho negativo no trabalho, com prejuízos à auto-estima e aos vínculos laborais e; (c) Desejo de se desvincular da organização em função da não-identificação com seus objetivos.

Verifica-se nos estudos apresentados que o mal-estar não é definido a priori. Ele é considerado como sendo as vivências derivadas das situações de trabalho que diferem de um lugar para outro. Além disso, está associado às questões de sofrimento no trabalho, evidenciando a dificuldade de se encontrar coerência nas definições.

Neste estudo, utiliza-se a definição de mal-estar no trabalho da Ergonomia da Atividade Aplicada à Qualidade de Vida no Trabalho - EAAQVT, abordagem teóricometodológica adotada para a pesquisa. Segundo essa abordagem, mal-estar no trabalho é:

Um sentimento desagradável que se origina das situações vivenciadas pelo(s) indivíduo(s) na execução das tarefas. A manifestação individual ou coletiva do mal-estar no trabalho se caracteriza pela vivência de sentimentos (isolados ou associados) que ocorrem, com maior frequência, nas seguintes modalidades: aborrecimento, antipatia, aversão, constrangimento, contrariedade, decepção, desânimo, desconforto, descontentamento, desrespeito, embaraço, incômodo, indisposição, menosprezo, ofensa, perturbação, repulsa, tédio. A vivência duradoura deste sentimento pelos trabalhadores constitui um fator de risco para a saúde nas situações de trabalho e indica ausência de QVT. (Ferreira, 2013, pp. 180-181)

Estudos recentes realizados com base na EAAQVT (Albuquerque, 2011; Andrade, 2011; Branquinho, 2010; Daniel, 2012; Feitosa, 2010; Fernandes, 2013) apontam que o fator organização do trabalho é a principal fonte de malestar no trabalho e que as vivências de bem-estar e malestar no trabalho estão vinculadas aos fatores estruturantes de QVT. Dessa forma, para se remover ou atenuar os indicadores críticos relacionados às exigências do trabalho, os pesquisadores sinalizam a importância de se atuar nos aspectos que compõe a QVT: condições e organização do trabalho, relações socioprofissionais, reconhecimento e crescimento profissional e elo trabalho-vida social.

Na mesma perspectiva, resgatando o conceito proposto por Ferreira e Seidl (2009), verifica-se que é fundamental considerar o Contexto de Produção de Bens e Serviços, composto por três dimensões articuladas: Condições de Trabalho, Organização do Trabalho e Relações
Socioprofissionais. Esses fatores estão presentes na base teórico-metodológica da Ergonomia da Atividade aplicada à Qualidade de Vida no Trabalho - EAAQVT (Ferreira, 2013).

Parte-se da premissa de que a QVT é composta por fatores estruturantes (Condições de Trabalho, Organização do Trabalho, Relações Socioprofissionais, Reconhecimento e Crescimento Profissional e Elo Trabalho-Vida social) que promovem bem-estar ou mal-estar no trabalho a depender do custo humano do trabalho e da eficácia das estratégias de mediação coletiva. Em outras palavras, QVT é identificada com base no continuum de representações que os trabalhadores expressam sobre as vivências de bemestar e mal-estar no contexto de trabalho. Os fatores são descritos na Tabela 1.

Considerando o cenário de trabalho no serviço público brasileiro e com base na abordagem de Qualidade de Vida no Trabalho anteriormente apresentada, hipotetizase globalmente que os trabalhadores deste instituto experimentarão vivências de mal-estar no trabalho, em função das diversas pressões e transformações em sua realidade organizacional, que não se distancia do contexto do serviço público com um todo. Entretanto, como este estudo situa-se teórico metodologicamente no viés da ergonomia da atividade, cabe esclarecer que seu objetivo não é o de testar hipóteses, mas de descrever uma dada realidade de trabalho para compreender as representações dos trabalhadores e traçar, em conjunto, alternativas para resgatar suas vivências positivas no trabalho.

Este estudo teve como objetivo geral identificar as representações que servidores e colaboradores manifestam sobre o mal-estar no trabalho em um Instituto Federal de Pesquisa no Brasil. Especificamente, objetivou-se: (a) analisar como os servidores e colaboradores caracterizam no órgão: as condições, a organização e as relações socioprofissionais de trabalho, as possibilidades de reconhecimento/crescimento profissional e o elo trabalhovida social e; (b) mapear as fontes de mal-estar.

Os dados apresentados neste artigo são o recorte de um projeto maior, intitulado Diagnóstico de QVT em um Instituto Federal de Pesquisa. Em função do volume de informação gerada em cada uma das etapas do diagnóstico, optou-se por apresentar, aqui, apenas os dados referentes a mal-estar no trabalho. Esta escolha justifica-se pela necessidade de se aprofundar o debate sobre esta questão em específico.

A relevância deste estudo inscreve-se em três dimensões: social, acadêmica e institucional. Do ponto de vista social, o interesse por questões relacionadas ao malestar no trabalho evidencia o caráter inexorável do trabalho na existência humana e sua importância ontológica. Do 
Tabela 1

Descrição dos fatores estruturantes de QVT

Fator 1: Condições de Trabalho $(\alpha=0,90)$

Expressa as condições físicas (local, espaço, iluminação, temperatura), materiais (insumos), instrumentais (equipamentos, mobiliário, posto), suporte (apoio técnico) que influenciam a atividade de trabalho e colocam em risco a segurança física. Esse fator é constituído de 12 itens. Exemplo: "O local de trabalho é confortável".

\section{Fator 2: Organização do Trabalho $(\alpha=0,73)$}

Expressa as variáveis de tempo (prazo, pausa), controle (fiscalização, pressão, cobrança), traços das tarefas (ritmo, repetição), sobrecarga e prescrição (normas) que influenciam a atividade de trabalho. Esse fator é constituído de 9 itens. Exemplo: "No [nome do órgão], as tarefas são repetitivas".

\section{Fator 3: Relações Socioprofissionais $(\alpha=0,89)$}

Interações socioprofissionais em termos de relações com os pares (ajuda, harmonia, confiança), com as chefias (liberdade, diálogo, acesso, interesse, cooperação, atribuição e conclusão de tarefas), comunicação (liberdade de expressão), ambiente harmonioso e conflitos que influenciam a atividade de trabalho. Esse fator é constituído de 16 itens. Exemplo: " $E$ comum o conflito no ambiente de trabalho".

\section{Fator 4: Reconhecimento e Crescimento Profissional $(\alpha=0,91)$}

Expressa variáveis relativas ao reconhecimento no trabalho (existencial, institucional, realização profissional, dedicação, resultado alcançado) e ao crescimento profissional (oportunidade, incentivos, equidade, criatividade, desenvolvimento), que influenciam a atividade de trabalho. Esse fator é constituído de 14 itens. Exemplo: "Sinto-me reconhecido pela instituição onde trabalho".

\section{Fator 5: Elo Trabalho-Vida Social $(\alpha=0,80)$}

Expressa as percepções sobre a instituição, o trabalho (prazer, bem-estar, zelo, tempo passado no trabalho, sentimento de utilidade, reconhecimento social) e as analogias com a vida social (casa, família, amigos) que influenciam a atividade de trabalho. Esse fator é constituído de 10 itens. Exemplo: "A sociedade reconhece a importância do meu trabalho".

Fonte: Ferreira (2013)

ponto de vista das organizações, estudar o mal-estar no trabalho permite compreender e intervir nos problemas do contexto de trabalho que colocam em xeque o bem-estar dos trabalhadores e a eficiência e eficácia organizacionais. Por fim, do ponto de vista acadêmico, a importância do tema reflete o papel e as possibilidades de intervenção das ciências do trabalho e da saúde tendo em vista a tríade indivíduo-trabalho-organização (Ferreira, 2013).

\section{Método}

\section{Caracterização do Campo}

O Instituto federal de pesquisa onde se desenvolveu este estudo é uma fundação pública federal vinculada à Presidência da República. Sua principal função é desenvolver atividades de planejamento e pesquisa, fornecendo suporte técnico e institucional às ações governamentais para a formulação e reformulação de políticas públicas e programas de desenvolvimento brasileiros. A sede do instituto encontra-se em Brasília e há ainda um escritório regional em outro estado do país. O total de trabalhadores do órgão, na época da pesquisa, era de 985 pessoas, sendo 577 servidores, 233 terceirizados, 144 bolsistas e 38 estagiários. No entanto, no momento da coleta de dados, 173 servidores e colaborados estavam ausentes por motivo de férias, afastamentos ou licenças, o que gerou uma população de 812 pessoas para aplicação do instrumento.

\section{Participantes}

A amostra do estudo é não probabilística por conveniência, de resposta voluntária, uma vez que as pessoas escolhem participar ou não. Segundo Moore (2011), nesse tipo de amostra, pessoas com maior interesse ou com opiniões contundentes têm maior probabilidade de responder. Com base em fórmula amostral para determinação de amostra aleatória (Barbetta, 2002), eram necessários 268 participantes ao nível de significância de $95 \%$.

Participaram da pesquisa 275 trabalhadores, sendo 
82 mulheres e 153 homens (40 não identificados), entre servidores e colaboradores (terceirizados, estagiários e bolsistas), o que corresponde a $33,86 \%$ do total de trabalhadores $(\mathrm{N}=812)$ do instituto no momento da pesquisa.

O perfil demográfico dos participantes apresentou as seguintes características: $36,72 \% \quad(\mathrm{n}=101)$ declararamse com título de especialista, mestre ou doutor e $24,36 \%$ $(\mathrm{n}=67)$ com nível de escolaridade superior completo. A média de idade foi igual a 37,70 anos $(\mathrm{DP}=12,40)$. Com relação ao estado civil, a amostra foi constituída por $40 \%$ de pessoas casadas $(\mathrm{n}=110)$.

No que se refere ao perfil profissiográfico, verifica-se que, dos que marcaram o vínculo com o órgão, 136 eram servidores, 60 terceirizados, 22 bolsistas e 09 estagiários. $65 \%$ dos servidores e colaboradores $(n=179)$ estavam lotados em Brasília e o tempo médio de trabalho no instituto era de 8,40 anos $(\mathrm{DP}=11,20)$.

\section{Instrumento}

Como instrumento, foi utilizada a versão eletrônica do Inventário de Avaliação de Qualidade de Vida no Trabalho IAQVT $(\alpha=0,94)$. O IAQVT é composto por uma parte quantitativa: 61 itens associados a uma escala de resposta tipo Likert de 11 pontos de concordância que mensuram os fatores condições de trabalho $(\alpha=0,90)$, organização do trabalho $(\alpha=0,73)$, relações socioprofissionais $(\alpha=0,89)$, reconhecimento e crescimento profissional $(\alpha=0,91)$ e elo trabalho-vida social $(\alpha=0,80)$ e; uma parte qualitativa composta por quatro questões abertas, a saber: "Na minha opinião, qualidade de vida no trabalho é...", "Quando penso no meu trabalho no [órgão], o que me causa mais bem-estar é...", "Quando penso no meu trabalho no [órgão], o que me causa mais mal-estar é..." e "Comentários e sugestões". No presente estudo serão apresentados os resultados referentes aos dados quantitativos que indicaram fontes de mal-estar no trabalho e à questão "Quando penso no meu trabalho no [órgão], o que me causa mais mal-estar é...".

O inventário permite conhecer, com rigor científico, o que pensam os respondentes sobre a Qualidade de Vida no Trabalho (QVT) em uma dada organização. Trata-se de um instrumento científico validado (Ferreira, 2009) e que foi desenvolvido com base em diversas pesquisas realizadas pelo ErgoPublic - Grupo de Estudos e Pesquisas em Ergonomia Aplicada ao Setor Público, do Instituto de Psicologia da Universidade de Brasília. A descrição de cada fator e os índices psicométricos são apresentados na Tabela 1.

Entre as utilidades o IAQVT destaca-se:

$\checkmark$ Realizar um diagnóstico rápido, com rigor científico, de como os servidores e colaboradores avaliam a Qualidade de Vida no Trabalho (QVT) na organização na qual trabalham;

$\checkmark$ Mapear indicadores (comportamentais, epidemiológicos e perceptivos) de QVT que auxiliam na gestão do Programa de Qualidade de Vida no Trabalho (PQVT);

$\checkmark$ Gerar subsídios fundamentais para a concepção de uma política de QVT e um Programa de Qualidade de Vida no Trabalho (PQVT) com base nas expectativas e necessidades apontadas pelos respondentes;

$\checkmark$ Monitorar, longitudinalmente, a evolução da QVT na organização.

\section{Procedimentos}

A primeira etapa do diagnóstico consistiu em uma campanha de sensibilização para aumentar o número de respondentes por meio de mensagens eletrônicas, boletins impressos, chamadas no site da intranet e inserções em eventos específicos, como workshops, oficinas e entrevistas para meios de comunicação internos. Houve um comunicado da direção da organização para todos os gestores, orientando sobre a importância da pesquisa, os cuidados essenciais para evitar constrangimentos e ações para estimular a participação dos trabalhadores, como o envio de cartasconvite às equipes subordinadas. Como ação adicional, a equipe gestora do projeto, interna à organização, entrou em contato, por telefone, com todos os gestores, ratificando o convite para a participação, fornecendo orientações e esclarecimentos adicionais.

Para garantir o sigilo, senhas individuais foram impressas em filipetas adesivas lacradas, e foram disponibilizadas em um grande recipiente transparente na entrada dos prédios, na sede e na regional, por onde todos os trabalhadores entravam e saiam. Os trabalhadores eram convidados, pela equipe do projeto, a escolher uma senha e informados de que ela era individual e instransferível. Cada respondente, então, entrava em um site externo à organização e, mediante a digitação da senha, era encaminhado para uma página que explicava o conteúdo da pesquisa, o tratamento sigiloso das informações e a perspectiva da apresentação dos resultados. Uma vez que o participante concordasse com os termos de participação, ele era direcionado para as telas de respostas, que não precisavam obrigatoriamente ser preenchidas para que ele avançasse na pesquisa. Ao final, havia uma tela com dados demográfica, a qual também não previa obrigatoriedade de resposta.

Além disto, apenas os pesquisadores tiveram acesso aos dados brutos da pesquisa, tendo sido repassado à organização tão somente os dados agrupados e ainda sim com o cuidado de não identificar participantes de áreas específicas (por exemplo, áreas com um baixo volume 
Tabela 2

Parâmetros básicos de análise

\begin{tabular}{|c|c|c|c|c|c|c|c|c|c|}
\hline $0-0,9$ & $\begin{array}{l}--- \\
1-1,9\end{array}$ & $2-2,9$ & $3-3,9$ & $\begin{array}{c}\text { Tendência } \\
\text { Negativa 4-4,9 }\end{array}$ & $\begin{array}{c}\text { Tendência } \\
\text { Positiva 5-5,9 }\end{array}$ & $\begin{array}{c}+ \\
6-6,9 \\
\end{array}$ & $\begin{array}{c}++ \\
7-7,9\end{array}$ & $\begin{array}{l}+++ \\
8-8,9 \\
\end{array}$ & $\begin{array}{c}++++ \\
9-10\end{array}$ \\
\hline \multicolumn{2}{|c|}{$\begin{array}{c}\text { Mal-Estar In- } \\
\text { tenso }\end{array}$} & \multicolumn{2}{|c|}{$\begin{array}{l}\text { Mal-Estar } \\
\text { Moderado }\end{array}$} & \multirow{2}{*}{\multicolumn{2}{|c|}{ Zona de Transição }} & \multicolumn{2}{|c|}{$\begin{array}{l}\text { Bem-Estar } \\
\text { Moderado }\end{array}$} & \multicolumn{2}{|c|}{$\begin{array}{c}\text { Bem-Estar } \\
\text { Intenso }\end{array}$} \\
\hline \multicolumn{4}{|c|}{ Mal-Estar Dominante } & & & \multicolumn{4}{|c|}{ Bem-Estar Dominante } \\
\hline \multicolumn{4}{|c|}{$\begin{array}{l}\text { Resultado negativo que evidencia } \\
\text { a predominância de representações } \\
\text { de mal-estar no } \\
\text { Representações que devem ser } \\
\text { transformadas no no } \\
\text { organizacional. }\end{array}$} & \multicolumn{2}{|c|}{$\begin{array}{l}\text { Resultado mediano. Indicador de } \\
\text { "situação-limite". Coexistência de } \\
\text { mal- estar e bem-estar no trabalho. }\end{array}$} & \multicolumn{4}{|c|}{$\begin{array}{l}\text { Resultado positivo que evidencia a } \\
\text { predominância de representações de } \\
\text { bem-estar no trabalho. Represen- } \\
\text { tações que devem ser mantidas e } \\
\text { consolidadas no ambiente organiza- } \\
\text { cional. }\end{array}$} \\
\hline
\end{tabular}

Risco de Adoecimento

Estado de alerta

Promoção de Saúde

Fonte: Ferreira (2013)

Tabela 3

Média, DP e Zona dos Fatores

\begin{tabular}{lccl}
\hline Fator & Média & DP & Zona \\
\hline QVT Global & 6,45 & 1,35 & Bem-Estar Moderado \\
Condições de Trabalho & 7,18 & 1,81 & Bem-Estar Moderado \\
Organização do Trabalho & 4,98 & 1,60 & Zona de transição/Tendência Negativa \\
Relações Socioprofissionais & 6,78 & 1,81 & Bem-Estar Moderado \\
Reconhecimento e Crescimento Profissional & 5,65 & 2,18 & Zona de transição/Tendência Positiva \\
Elo Trabalho-Vida Social & 7,54 & 1,43 & Bem-Estar Moderado \\
\hline
\end{tabular}

de respondentes foram tratadas em conjunto com outras, para evitar a identificação dos participantes). O inventário ficou disponível para os respondentes no site externo à organização durante 21 dias.

\section{Análise de Dados}

Os dados quantitativos foram tratados por meio do software SPSS, versão $18.0 \mathrm{e}$, para análise, foram geradas estatísticas descritivas dos itens e dos cinco fatores. Assim, os valores das médias são classificados com base na cartografia apresentada na Tabela 2.

Para análise da parte qualitativa, foi utilizado o programa Alceste - Análise Lexical de Contexto de um Conjunto de Segmentos de Textos (Reinert, 1990), versão 4,7. O Alceste identifica fragmentos que são representativos do discurso com o objetivo de extrair as classes ou os Núcleos Temáticos Estruturadores do Discurso (NTED). Esses núcleos são formados por enunciados linguísticos dos participantes da pesquisa que representam o conjunto textual centrado em um tema.

\section{Resultados}

Os resultados da parte quantitativa do IAQVT evidenciam que $65,69 \% \quad(n=180)$ dos respondentes percebem predominância de bem-estar no trabalho, 28,10\% $(n=77)$ dos trabalhadores apresentam representações que estão localizadas na zona de transição, onde coabitam o mal-estar e o bem-estar no trabalho e 6,20\% $(n=17)$ dos trabalhadores percebem mal-estar no trabalho dominante. Não se identificou, nas análises quantitativas, diferenças significativas entre os contratos de trabalho, no que se referiu à percepção de mal-estar no trabalho. Os resultados dos fatores estruturadores da qualidade de vida no trabalho na ótica da ergonomia da atividade indicam, segundo a cartografia psicométrica de interpretação, estado crítico para organização do trabalho e reconhecimento e crescimento 
Tabela 4

Médias e desvios-padrão dos itens de cada fator

\section{Itens do fator Condições de Trabalho}

Item

Média/Desvio Padrão

Há cobrança de prazos para o cumprimento de tarefas

$2,69(2,50)$

Existe fiscalização do desempenho

$3,54(2,94)$

As normas para execução das tarefas são rígidas

$3,92(3,30)$

No [nome do órgão], existe forte cobrança por resultados

$4,74(2,96)$

No [nome do órgão], as tarefas são repetitivas

$5,03(3,23)$

$5,78(2,99)$

$5,94(3,35)$

$6,03(2,70)$

$6,31(2,83)$

Itens do fator Reconhecimento e Crescimento Profissional

Item

As oportunidades de crescimento profissional são iguais para todos

No [nome do órgão], recebo incentivos de minha chefia

O [nome do órgão], oferece oportunidade de crescimento profissional

Há incentivos do [nome do órgão], para o crescimento na carreira

O reconhecimento do trabalho individual é uma prática efetiva no [nome do órgão]

Sinto-me reconhecido pela instituição onde trabalho

O reconhecimento do trabalho coletivo é uma prática efetiva no [nome do órgão]

O desenvolvimento pessoal é uma possibilidade real no [nome do órgão]

Falta apoio das chefias para o meu desenvolvimento profissional

No [nome do órgão], minha dedicação ao trabalho é reconhecida

No [nome do órgão], o resultado obtido com meu trabalho é reconhecido

Tenho a impressão de que para o [nome do órgão] eu não existo

A prática do reconhecimento contribui para a minha realização profissional

Tenho a possibilidade de ser criativo no meu trabalho
Média/Desvio Padrão

$3,76(3,22)$

$4,49(2,78)$

$4,89(3,37)$

$4,97(3,33)$

$5,09(2,98)$

$5,18(3,21)$

$5,31(2,93)$

$5,96(2,98)$

$6,13(3,19)$

$6,18(3,13)$

$6,31(2,96)$

$6,46(3,22)$

$6,80(3,15)$

$6,96(2,89)$

\section{Itens do fator Elo Trabalho-Vida Social}

Item

A sociedade reconhece a importância do meu trabalho

O tempo de trabalho que passo no [nome do órgão] me faz feliz

No [nome do órgão], as atividades que realizo são fonte de prazer

O trabalho que faço é útil para a sociedade

Sinto que o meu trabalho no [nome do órgão], me faz bem

No [nome do órgão], disponho de tempo para executar o meu trabalho com zelo

Sinto-me mais feliz no trabalho no [nome do órgão] que com os amigos

Sinto-me mais feliz no trabalho no [nome do órgão] que em minha casa

Gosto da instituição onde trabalho

Sinto-me mais feliz no trabalho no [nome do órgão] que com a minha família
Média/Desvio Padrão

$5,91(3,05)$

$6,70(2,84)$

$6,99(2,54)$

$7,31(3,03)$

$7,46(2,55)$

$7,77(2,19)$

$8,24(2,22)$

$8,28(2,32)$

$8,33(2,15)$

$8,82(2,02)$ 
profissional; e bem-estar dominante para condições de trabalho, relações socioprofissionais e elo trabalho-vida social (Tabela 3, acima).

Apesar do número relativamente baixo de pessoas que consideraram o mal-estar como predominante e de nenhum fator estar situado na zona de mal-estar, é preciso dar atenção aos trabalhadores que avaliaram negativamente a qualidade de vida no trabalho, pois estes estão em risco de adoecimento ou já adoecidos. Ademais, ressalta-se a necessidade de um olhar mais apurado sobre outras fontes explicativas desta representação, que podem se revelar nos itens dos fatores do IAQVT. Na Tabela 4 (página anterior) estão relacionados os itens de cada fator

O fator Condições de Trabalho foi o segundo melhor avaliado pelos participantes da pesquisa, situando na zona de bem-estar moderado. As médias dos itens desse fator indicam predominância de vivências de bem-estar no que se refere ao ambiente físico de trabalho, ao mobiliário e ao fornecimento de materiais e equipamentos adequados para a realização das atividades.

No que se refere ao fator Organização do Trabalho, verifica-se na análise das médias dos itens, os aspectos que contribuem para que esse fator tenha tido a avaliação mais negativa. Os itens considerados mais críticos demonstram que a rigidez das normas, a fiscalização do desempenho e a cobrança de prazos para o cumprimento das tarefas são as principais fontes de mal-estar no instituto para este fator. Em "situação-limite", indicando estado de alerta, encontram-se a forte cobrança por resultados, o ritmo excessivo de trabalho e as tarefas repetitivas.

O relacionamento trabalhador-chefia, a comunicação e a divisão da tarefas foram avaliados como medianos, situandose na zona de transição, no que diz respeito às relações socioprofissionais. A coexistência de bem-estar e mal-estar para esse fator fica evidente ao se observar que aspectos como o relacionamento entre colegas, a liberdade para se realizar uma tarefa e a relação com a chefia imediata foram avaliados positivamente.

O fator Reconhecimento e Crescimento Profissional é um dos mais críticos no instituto pesquisado. Verificase que, de um total de 14 itens, a metade encontra-se na zona de transição. Além disso, o item "as oportunidades de crescimento profissional são iguais para todos" foi o pior avaliado, situando-se na zona de mal-estar moderado. Destaca-se também que os trabalhadores da pesquisa não percebem o reconhecimento do seu trabalho pela sociedade, no fator Elo Trabalho-Vida Social.

Com relação à parte qualitativa, a questão "Quando penso no meu trabalho no órgão (...), o que me causa mais mal-estar é..." foi respondida por 229 trabalhadores. Foram identificados, para efeitos de análise, quatro núcleos temáticos que compõe as principais fontes de mal-estar no trabalho no contexto do instituto pesquisado: Gestão organizacional (40\%); Injustiças e falta de autonomia (22\%); Desigualdade de tratamento entre cargos e carreira e; Espaço de trabalho e falta de planejamento (17\%).

Os núcleos temáticos se referem a quatro categorias que descrevem as representações que servidores e colaboradores têm acerca do mal-estar no trabalho. Verbalizações típicas do discurso desses trabalhadores são apresentadas na Tabela 5.

Em suma, os resultados do estudo fornecem um conjunto de indicadores críticos que são fontes de mal-estar no trabalho no instituto: gestão organizacional e do trabalho, desigualdades e injustiças e falta de valorização. Para se remover ou, ao menos, atenuar estes indicadores devem ser criados princípios, planos e ações, com a participação ativa dos trabalhadores, que atuem nas causas dos problemas evidenciados.

\section{Discussão}

Os resultados indicam que as condições de trabalho no instituto são, globalmente, satisfatórias. Entretanto, a categoria Espaço de trabalho e falta de planejamento destaca que há locais onde os trabalhadores se sentem incomodados com o ambiente físico de trabalho. Condições físicas e de suporte organizacional adequadas são aspectos indispensáveis para a promoção da qualidade de vida no trabalho porque reduzem os riscos para a saúde e segurança dos trabalhadores. Ademais, facilitam a realização das atividades, de acordo com as necessidades do trabalhador e das exigências do trabalho (Ferreira, 2008b). Considerando a pressão por resultados sofrida pelos trabalhadores nos últimos, importa destacar que, sem estrutura adequada, dificilmente pode-se realizar um trabalho de qualidade. Mas, pior que isso, é o que parece ocorrer no instituto: trabalhos de qualidade são realizados mesmo em condições de trabalho dificultosas (apesar de não críticas), o que pode invalidar, para a organização, as queixas dos trabalhadores e levar o desconforto como planejamento, por exemplo, a situações limítrofes.

O fator Organização do Trabalho, no que se refere às médias dos itens, recebeu as avaliações mais negativas. Concomitantemente, encontra-se nos resultados qualitativos a categoria Gestão Organizacional que descreve pressão na execução de atividades e ingerências administrativo-financeiras e de pessoal. Para Guimarães (2009), as mudanças ocorridas no serviço público alteraram o ritmo de trabalho, a natureza e a divisão de tarefas, as exigências em termos de resultados esperados e os procedimentos prescritos, aspectos estes da organização do trabalho evidenciadas no instituto. Simultaneamente a tais mudanças, tem-se o despreparo gerencial para lidar 
Tabela 5

Verbalizações Típicas

\begin{tabular}{|c|c|}
\hline Nú & Verbalização típica \\
\hline \multirow{3}{*}{$\begin{array}{l}\text { Gestão } \\
\text { Organizacional }\end{array}$} & $\begin{array}{l}\text { A incompetência e ignorância dos gestores na aplicação das legislações que guarnecem o respeito e } \\
\text { dignidade das pessoas e dos bens públicos. }\end{array}$ \\
\hline & $\begin{array}{l}\text { O fato de estar trabalhando em Brasília, quando minha família mora [em outro estado]. A despeito } \\
\text { de existir uma unidade do [instituto] naquela cidade e de não haver impedimentos para que eu } \\
\text { realizasse minhas tarefas naquela unidade, a direção do [instituto] tem como questão fechada a não } \\
\text { alocação de novos servidores naquela unidade. }\end{array}$ \\
\hline & Estar sobre pressão o tempo todo. \\
\hline \multirow[t]{2}{*}{$\begin{array}{l}\text { Espaço de } \\
\text { trabalho e falta } \\
\text { de planejamento }\end{array}$} & $\begin{array}{l}\text { A demanda excessiva de trabalho, o quadro técnico insuficiente e o fato de a área meio, em grande } \\
\text { parte, não compreender o trabalho técnico e não prestar as atividades de apoio de modo satisfatório. } \\
\text { Algumas vezes, realizar o trabalho em prazos muito exíguos devido à desorganização de outros } \\
\text { setores. }\end{array}$ \\
\hline & $\begin{array}{l}\text { A falta de beleza, ergonomia e segurança do meu local de trabalho, da minha sala em especial. O } \\
\text { barulho de outros colegas nas salas contiguas. }\end{array}$ \\
\hline \multirow{2}{*}{$\begin{array}{l}\text { Desigualdade de } \\
\text { tratamento entre } \\
\text { cargos e carreira }\end{array}$} & $\begin{array}{l}\text { Pouca valorização dos servidores ativos da casa, inclusive no provimento dos cargos de confiança. } \\
\text { Muita segregação funcional, uma espécie de apartheid entre os servidores atividade fim e a atividade } \\
\text { meio. }\end{array}$ \\
\hline & $\begin{array}{l}\text { Isolamento profissional; a competição técnica espúria; a falta de conversas técnicas apropriadas; as } \\
\text { amizades e os grupelhos internos; as fofocas de corredor; a falta de reconhecimento profissional; a } \\
\text { falta de meritocracia; a falta de respeito a hierarquias e regras. }\end{array}$ \\
\hline \multirow{3}{*}{$\begin{array}{l}\text { Injustiças e falta } \\
\text { de autonomia }\end{array}$} & $\begin{array}{l}\text { Saber que vou me estressar com pessoas que não realizam suas tarefas, me deixando sobrecarregada } \\
\text { e mesmo assim não terei o reconhecimento da minha chefia. }\end{array}$ \\
\hline & $\begin{array}{l}\text { Saber que não posso ter um diálogo amigável com meu superior, que na atual chefia não existe } \\
\text { respeito com o funcionário terceirizado e aqui não temos valor em nada que fazemos. }\end{array}$ \\
\hline & $\begin{array}{l}\text { Ver que alguns pesquisadores não aparecem no [instituto] e mesmo assim são reconhecidos. Vejo que } \\
\text { ha pautada por questões políticas. }\end{array}$ \\
\hline
\end{tabular}

com os novos contextos e exigências, de maneira que, regra geral, os gestores terminam por exercer pressão e controle exacerbados, estando, além disso, despreparados em termos de treinamento para gestão.

Os achados relacionados à organização do trabalho e às categorias Gestão Organizacional, Espaço de trabalho e falta de planejamento e Injustiças e falta de autonomia evidenciam a necessidade de capacitação da equipe de gestão do órgão para que as normas, a fiscalização, a cobrança e os prazos sejam adaptados à realidade dos trabalhadores e, possam ser definidos juntamente com quem mais entende do trabalho: o trabalhador que o executa. Isso envolve, na ótica da EAAQVT, a postura gerencial e os traços da tarefa (Ferreira, 2013). Ressalta-se que itens relacionados à rigidez das normas, à forte cobrança por resultados, ao ritmo excessivo de trabalho, às tarefas repetitivas, à fiscalização do desempenho e à cobrança de prazos para o cumprimento das tarefas são as principais fontes de mal-estar no instituto e estão estreitamente relacionados à organização do trabalho, aos modos de gestão e à intensificação do trabalho como destacam Antloga et al., (2014); Dal Rosso (2008), Ferreira (2008a, 2008b, 2013) e Ferreira et al. (2009).

A postura gerencial promotora de QVT deve garantir uma gestão participativa, ou seja, permitir que os trabalhadores participem das tomadas de decisão; demonstrar preocupação não só com o desempenho, mas também com o bem-estar da equipe por meio do respeito e do interesse pelos membros da equipe e; ter práticas de reconhecimento. Com relação aos traços da tarefa, estas devem estar alinhadas com as características do trabalhador e das situações reais de trabalho. Nesse sentido, as normas e o controle devem ser facilitadores da execução do trabalho. Além disso, para "quebrar" a monotonia das tarefas repetitivas, deve-se dar espaço para a autonomia e a liberdade, permitindo que o trabalhador lance mão de soluções criativas nas situações de trabalho. 
A constatação, no presente estudo, de que o fator organização do trabalho foi o pior avaliado corrobora outras pesquisas que utilizaram a abordagem da EAAQVT (Albuquerque, 2011; Andrade, 2011; Branquinho, 2010; Daniel, 2012; Feitosa, 2010; Fernandes, 2013; Figueira, 2014). Nestas, a organização do trabalho também ficou localizada na zona de transição. Nesse sentido, é plausível inferir que a organização do trabalho é a principal fonte de mal-estar no trabalho no contexto do serviço público. Ressalta-se, por isso, a necessidade de se pesquisar mais profundamente este fator.

Em se tratando dos itens críticos do fator relações socioprofissionais e das verbalizações das categorias Desigualdade de tratamento entre cargos e carreira e Injustiças e falta de autonomia, destaca-se que a clareza e a liberdade na comunicação são fatores fundamentais na promoção de bem-estar no trabalho (Ferreira \& Seidl, 2009; Maciel, Sena, \& Sabóia, 2006). Ademais, Ferreira (2008b; 2013) afirma que o relacionamento socioprofissional está intimamente ligado à satisfação dos trabalhadores e à desempenhos mais adequados diante das exigências impostas pelas situações de trabalho. As relações socioprofissionais tem um papel compensador fundamental para as vivências de bem-estar no trabalho quando outros aspectos da organização estão críticos. No caso do instituto pesquisado, é possível que a existência de relacionamentos saudáveis amenizem os aspectos negativos da organização do trabalho e da falta de reconhecimento e de oportunidades de crescimento. Todavia, vale ressaltar, como afirmaram Antloga et al. (2014), que as relações socioprofissionais são afetadas diretamente por uma organização do trabalho problemática e que pode ser que no instituto elas também comecem a ser prejudicadas em função das diversas dificuldades já citadas.

$\mathrm{O}$ apartheid funcional mencionado por um participante (apresentado, nos resultados, como verbalização típica), refere-se à divisão entre a área fim (pesquisadores) e área meio como um todo (onde situam-se colaboradores, terceirizados e estagiários). Na realidade, na instituição, a rotatividade funcional de terceirizados é baixa, ao contrário de outros lugares, dentro mesmo do serviço público. A grande questão neste órgão é que os pesquisadores podem ter horário flexível, conduzir sua jornada de maneira mais livre e, além disso, tem seu trabalho reconhecido em relatórios e diversas exposições na mídia. Por outro lado, a área meio é "esquecida", pouco valorizada e reconhecida. Está submetida a horários rígidos de trabalho, prescrição exagerada de tarefas e pouca margem de manobra no que se refere às metas, tendo, ainda, que, ao mesmo tempo, dar suporte e fiscalizar o trabalho da área fim.

As oportunidades de crescimento são essenciais para promoção de QVT (Albuquerque, 2011; Ferreira, 2008b,
2013). Por outro lado, a falta de oportunidades de crescimento potencializa vivências de mal-estar no trabalho (Ferreira \& Seidl, 2009) e sofrimento no trabalho (Ferreira \& Mendes, 2001). O reconhecimento deve ser traduzido em práticas formais e informais que permitam ao trabalhador recuperar o sentido do trabalho para além do comprometimento com desempenho e resultados. Buscando, assim, a satisfação no trabalho (Ferreira, 2008b).

Dessa forma, para reduzir o descompasso entre as ações das organizações e o que os trabalhadores realmente precisam (Ferreira, 2013; Nogueira \& Frota, 2011) é necessário considerar os aspectos levantados pelos trabalhadores por meio de um espaço público e legítimo de fala, conforme preconiza Ferreira (2013). Para o autor, é fundamental a construção de um espaço organizacional que legitime e valorize a intersubjetividade, com base na premissa de que os trabalhadores devem ser sujeitos do seu trabalho e não objetos de produção. Identificar as fontes de mal-estar no trabalho é um requisito indispensável para a promoção da qualidade de vida no trabalho, pois permite que se atue nas causas dos problemas, amenizando-os e/ou removendo-os.

A pesquisa em si pode ser considerada uma prática de qualidade de vida no trabalho, pois formaliza um espaço público de expressão do pensamento no contexto institucional. Os resultados do presente estudo geram subsídios para a elaboração de políticas de QVT e de diretrizes voltadas para ações que promovam o bemestar dos trabalhadores, contribuindo para a melhoria da qualidade de vida no trabalho com uma política e um programa de QVT.

O estudo apresenta limites, pois foi realizado com uma amostra pequena, menos da metade do total de trabalhadores, sendo que a maioria dos participantes são servidores. Ademais, baseou-se em auto-relato. Por outro lado, a utilização do IAQVT permitiu o alcance dos objetivos, uma vez que foram identificados os aspectos críticos de cada fator estruturador da qualidade de vida no trabalho e, dessa forma, mapeou-se as fontes de mal-estar no trabalho no órgão investigado. Os resultados servem de subsídio para a criação de ações que promovam mudanças no contexto de trabalho e para a condução de pesquisas que busquem investigar as estratégias de mediação utilizadas pelos trabalhadores, ou seja, como eles lidam com as contradições presentes nessa realidade de trabalho para não adoecerem.

$\mathrm{O}$ instituto investigado nesta pesquisa é apenas um representante de um quadro que parece ser motivo de alarme: o mal-estar está disseminado no serviço público brasileiro como se este fosse uma engrenagem do sistema produtivista do capitalismo, e ele não é. A prestação de serviços públicos 
faz parte de uma cadeia de delicado equilíbrio, que envolve, antes de tudo, a questão da cidadania. A cidadania é para todos e só pode ser alcançada por meio de um estado forte, organizado e que promova serviços de qualidade. Por outro lado, para que isto seja possível, os trabalhadores também precisam ser cidadãos, ou seja, devem ter direito a voz, a acesso, a bem-estar. Permitir que haja mal-estar para esses trabalhadores pode comprometer a qualidade do seu trabalho e promover o contrário do que tem sido esperado: trabalhadores podem adoecer e comprometer a entrega de serviços de qualidade. Para além de todo o discurso de eficácia organizacional, que, sem dúvida, é pertinente e importante, vale a pena lembrar que a questão da cidadania, da dignidade e da saúde do trabalhador encontram-se inscritas na própria Constituição de nosso país. Garantir tais direitos não se trata, somente, de uma questão de eficiência. É, acima de tudo, uma questão de justiça.

\section{Referências}

Abrahão, J. I. (2000). Restruturação Produtiva e Variabilidade do Trabalho: Uma Abordagem da Ergonomia. Psicologia: Teoria e Pesquisa, 16(1), 4954.

Albuquerque, V. (2011). Qualidade de Vida no Trabalho, Bem-Estar e Mal-Estar Sob a Ótica de Trabalhadores de Uma Agência Reguladora no Brasil. (Dissertação de mestrado não publicada). Universidade de Brasília, Brasil.

Almeida, C. P. (2007). Custo humano, estratégias de mediação e cidadania: Atendimento presencial ao público em Agências da Presidência Social. (Tese de doutorado não publicada). Universidade de Brasília, Brasil.

Andrade, P. P. (2011). Sentimento de (In)justiça na Justiça: Fatores (Des)estruturantes de QVT Sob a Ótica dos Servidores de Um Órgão do Poder Judiciário. (Dissertação de mestrado não publicada). Universidade de Brasília, Brasil.

Antloga, C. S., Maia, M., Cunha, K., \& Peixoto, J. (2014). Contexto de Trabalho e Custo Humano no Trabalho em um órgão do Poder Judiciário Brasileiro. Ciência e Saúde Coletiva, 19(12), 4787-4796.

Antunes, R., \& Alves, G. (2004). As mutações no mundo do trabalho na era da mundialização do capital. Educação e Sociedade, 25(87), 335-351.

Araújo, T. M., Sena, I. P., Viana, M. A., \& Araújo, E. M. (2006) Mal-estar docente: Avaliação de condições de trabalho e saúde em uma instituição de ensino superior.
Revista Baiana de Saúde Pública, 29(1), 6-21.

Aznar, M. P. M., Rodriguez, M. A. G., \& Aznar, M. J. M. (2006). Estrés y malestar en el profesorado. International Journal of Psychology and Psychological Therapy, 6(1), 63-76.

Barbetta, P. A. (2002). Estatística Aplicada às Ciências Sociais. Florianópolis: Editora da UFSC.

Baumgarten, M. (2006). Reestruturação produtiva e industrial. In A. D. Cattani, \& L. Holzmann (Orgs.), Dicionário: Trabalho e tecnologia (pp. 237-239). Porto Alegre: Editora da UFRGS.

Beatriz, M. Z. (2010). O trabalho, a representação e o malestar do trabalhador: algumas reflexões. Revista Malestar e subjetividade, 10(4), 1107-1129.

Bendassolli, P. (2011). Mal-estar no trabalho: do sofrimento ao poder de agir. Revista Mal-estar e Subjetividade, 10(1), 63-98.

Branquinho, N. G. S. (2010). Qualidade de Vida no Trabalho e vivencias de bem-estar e mal-estar no trabalho em professores da rede pública de ensino de Unaí/MG. (Dissertação de Mestrado não publicada). Programa de Pós-Graduação em Psicologia Social, do Trabalho e das Organizações (PSTO), Universidade de Brasília, Brasília, DF, Brasil.

Brusiquese, R. G., \& Ferreira, M. C. (2012). Inovações tecnológicas e organizacionais em escritórios e os impactos na qualidade de vida no trabalho. Cadernos de Psicologia Social do Trabalho, 15(1), 1-16.

Chavez, R. C. (2009). Condiciones de trabajo y bienestar/ malestar docente em profesores de enseñanza media de Santiago de Chile. Educação e Sociedade, 30(107), 409-426.

Dal Rosso, S. (2008). Intensificação do trabalho - teoria e método. In S. Dal Rosso \& J. A. A. S. Fortes (Orgs.), Condições de trabalho no limiar do século XXI (pp. 21-36). Brasília: Épocca.

Daniel, J. B. (2012). "É-feito de coisas burocráticas": Impactos da organização do trabalho na qualidade de vida no trabalho em um órgão público federal. (Dissertação de Mestrado não publicada). Universidade de Brasília, Brasil.

Feitosa, L. R. C. (2010). E se a orquestra desafinar? Contexto de produção e qualidade de vida no trabalho dos músicos da Orquestra Sinfônica de Teresina/PI. (Dissertação de Mestrado não publicada). Programa de Pós-Graduação em Psicologia Social, do Trabalho e das Organizações (PSTO), Universidade de Brasília, 
Brasília, DF, Brasil.

Fernandes, L. C. (2013) "Estamos o tempo todo enxugando gelo": Qualidade de vida no trabalho e vivências de bem-estar e mal-estar em um órgão do poder judiciário. (Dissertação de Mestrado não publicada). Universidade de Brasília, Brasil.

Ferreira, M. C. (2008a). A Ergonomia da atividade se interessa pela qualidade de vida no trabalho? Reflexões empíricas e teóricas. Cadernos de Psicologia Social e do trabalho, 11, 83-99.

Ferreira, M. C. (2008b). O que pensam os trabalhadores franceses sobre as novas exigências no trabalho? Reflexões empíricas e teóricas. Cadernos de Psicologia Social e do Trabalho, 11, 83-99.

Ferreira, M. C. (2009). Inventário de Avaliação de Qualidade de Vida no Trabalho (IAQVT): Instrumento de Diagnóstico e Monitoramento de QVT nas Organizações. In Anais da $61^{a}$ Reunião da Sociedade Brasileira para o Progresso da Ciência, Manaus, AM, Brasil.

Ferreira, M. C. (2013). Qualidade de Vida no Trabalho: uma abordagem centrada no olhar dos trabalhadores (2a ed.). Brasília: Edições Ler, Pensar, Agir.

Ferreira, M. C., \& Mendes, A. M. (2001). "Só de pensar em vir trabalhar, já fico de mau humor": atividade de atendimento ao público e prazer-sofrimento no trabalho. Estudos de Psicologia, 6(1), 97-108.

Ferreira, M. C., \& Seidl, J. (2009). Mal-estar no trabalho: análise da cultura organizacional de um contexto bancário brasileiro. Revista Psicologia: Teoria e Pesquisa, 25(2), 245-254.

Ferreira, R. R., Ferreira, M. C., Antloga, C. S., \& Bergamaschi, V. (2009). Concepção e implantação de um programa de qualidade de vida no trabalho no setor público: o papel estratégico dos gestores. Revista de Administração, 44(2), 147-157.

Figueira, T. G. (2014). Bem-estar, mal-estar e qualidade de vida no trabalho em uma instituição pública brasileira. (Tese de doutorado não publicada). Universidade de Brasília, Brasil.

Freud, S. (1930/1996). O mal-estar na civilização. Rio de Janeiro: Imago.

Gil-Monte, P., \& Peiró, J.M. (1997). Desgaste psíquico en el trabajo: el sindrome de quemarse. Madri: Síntesis.

Guimarães, M. C. (2009). Transformações do trabalho e violência psicológica no serviço público brasileiro. Revista brasileira de Saúde ocupacional, 34(120),
163-171.

Maciel, R. H., Sena, F. C., \& Sabóia, I. B. (2006). O mal-estar nas novas formas de trabalho: Um estudo sobre a percepção do papel dos cooperados em uma cooperativa de trabalho autogestionário. Revista Malestar e subjetividade, 5-6(2), 535-560.

Maslach, C., \& Leiter M. P. (1999) Trabalho: fonte de prazer ou desgaste? Guia para vencer o estresse na empresa. Campinas, SP: Papirus.

Medeiros, L. F. R. (2011) "Somos a cara da prefeitura? Então somos a cara abandonada": Ergonomia da atividade aplicada à qualidade de vida no trabalho no contexto do serviço público municipal. (Tese de doutorado não publicada). Universidade de Brasília, Brasil.

Moore, D. S. (2011). A estatística básica e sua prática (5 ed.). Rio de Janeiro: LTC.

Neto, D. S. N. (2010). O mal-estar no trabalho: um estudo sobre suas formas de expressão no contexto do individualismo contemporâneo. (Tese de doutorado não publicada). Universidade do Estado do Rio de Janeiro, Brasil.

Nogueira, C. V., \& Frota, F. H. S. (2011). Qualidade de vida no trabalho: Percepções sobre sua importância como Política de Valorização no Serviço Público. Revista do Mestrado Profissional em Planejamento em Políticas Públicas, 1(3), 31-58.

Reinert, M. (1990). Alceste, une méthodologie d'analyse dês dones textuelles et une application. Bulletin de Methodologie Sociologique, 28, 23-32.

Sá, M. C. (2001). Subjetividade e projetos coletivos: malestar e governabilidade nas organizações de saúde. Ciência e Saúde Coletiva, 6(1), 151-164.

Silva, N. (2005). O mal-estar da professora alfabetizadora: contribuições de D. Winnicott. Mal-estar $e$ Subjetividade, 5(1), 11-44.

Sousa, A. A., \& Dela Coleta, M. F. (2012). O bem-estar no trabalho de psicólogos em serviços de saúde pública. Psicologia: ciência e profissão, 32(2), 404-421.

Timm, E. Z., Mosquera, J. J., \& Stobaus, C. D. (2010). O malestar na docência em tempos líquidos de modernidade. Mal-estar e Subjetividade, 10(3), 865-885. 


\section{Endereço para correspondência:}

Carla Sabrina Antloga

Endereço: SHCES 109, Bloco A, apartamento 405,

Cruzeiro, Brasília, DF, CEP 70.650-191

E-mail: antloga@unb.br, antlogacarla@gmail.com

\section{Endereço para correspondência:}

Izabela Pinheiro

SQN 106, Bloco B, apartamento 204, Asa Norte, Brasília, DF, CEP 70.742-020

E-mal: izabela_pinheiro@hotmail.com,

izabelampinheiro@gmail.com

\section{Endereço para correspondência:}

Marina Maia

CNB 10 Lotes 4/5, apartamento 1401, Taguatinga Norte, DF, CEP 72.115-105.

E-mail: m.maiacarmo@gmail.com

Endereço para correspondência:

Helena Karla Barbosa de Lima

E-mail: helenalima@unb.br 